\title{
ASPECTOS FARMACOLÓGICOS E TOXICOLÓGICOS DO ALCALOIDE N, N - DIMETILTRIPTAMINA (DMT)
}

\section{Autores: Lilian Carvalho Machado', Renan Honorato da Cruz¹, Soraia Sayuri Higa1, Thamires Raquel Barros Silva1, Thamyris Cavalcante Lima1, Robson Seriani ${ }^{2, A}$.}

${ }^{1}$ Acadêmicos do curso de farmácia da Universidade Anhembi Morumbi, São Paulo, Brasil.

²Orientador e docente da Universidade Anhembi Morumbi, São Paulo, Brasil.

\section{Informações do artigo}

Palavras Chave:

Dimetiltriptamina,

toxicidade,

efeitos terapêuticos

\section{Resumo}

A N, N - dimetiltriptamina (DMT) é um alcaloide alucinógeno presente nas folhas de Psychotria viridis, uma planta muito utilizada em chás que são ingeridos durante determinados rituais religiosos, sendo o chá de Ayahuasca um dos mais conhecidos. Devido sua semelhança com o neurotransmissor serotonina (5-HT), a DMT age de forma agonista nos receptores serotoninérgicos 5-HT1A, 5-HT2A e 5-HT2C, causando diversos efeitos como náuseas, tremores e mudança de humor, alguns relatos apontam alterações no sistema imunológico devido à diminuição dos níveis de linfócitos $\mathrm{CD} 3 \mathrm{e}$ CD4. No entanto, pesquisas recentes apontam, também, os efeitos terapêuticos da DMT, comprovando através de testes in vivo seu potencial antitumoral, antidepressivo e ansiolítico, além de auxiliar no tratamento contra o alcoolismo e tabaco. Considerando o uso crescente de chás que contêm a DMT, esse trabalho tem como objetivo descrever seus principais efeitos farmacológicos e toxicológicos em virtude da limitação de referências e a necessidade de compilação de dados dispersos na literatura. O presente estudo conclui que a DMT possui potencial farmacológico, porém também importantes efeitos adversos, incluindo toxicidade, o que corrobora com a necessidade da realização de mais testes agudos e crônicos, além de pesquisas epidemiológicas focadas na sua ação nas populações que a usam.

\footnotetext{
${ }^{\text {AAutor correspondente }}$

Robson Seriani - E-mail: robson.seriani@anhembi.br - ORCID: https://orcid.org/0000-0001-5086-6708
}

DOI: https://doi.org/10.31415/bjns.v3i1.84 - Artigo recebido em: 31 de janeiro de 2020 ; aceito em 15 de fevereiro de 2020 ; publicado em 10 de março de 2020. Brazilian Journal of Natural Sciences, Vol. 3, N.1, março 2020. Disponível online a partir de 10 de março de 2020, ISSN 2595-0584. www.bjns.com.br. Todos os autores contribuíram igualmente com o artigo. Os autores declaram não haver conflito de interesse. Este é um artigo de acesso aberto sob a licença CC - BY: http://creativecommons.org/licenses/by/4.0 


\section{Article ID}

Keywords:

Dimethyltryptamine, toxicity, therapeutic effects

\begin{abstract}
$\mathrm{N}, \mathrm{N}$ - dimethyltryptamine (DMT) is a hallucinogenic alkaloid present in the leaves of Psychotria viridis, a plant widely used in teas that are ingested during some religious ritual, ayahuasca tea is one of the most known. Consider its similarity to the neurotransmitter serotonin (5-HT), DMT acts as an age-agonist at the 5-HT1A, 5-HT2A and 5-HT2C serotonergic receptors, causing several effects such as nausea, tremors and mood changes, some reports indicated system immune changes due to lower levels of CD3 and CD4 lymphocytes. However, recent researches has also pointed out the therapeutic effects of DMT, proving through in vivo tests its antitumor, antidepressant and anxiolytic potential, in addition it helps in the treatment against alcoholism and tobacco. Considering the increasement use of DMT teas, this work aims to describe its main pharmacological and toxicological effects due to limited references and the need to compile data dispersed in the literature. The present study concludes that DMT has potential pharmacological action, but also important adverse effects, including toxicity, which corroborates the need of doing more acute and chronic tests, in addition to epidemiological research focused on its action in which users use.
\end{abstract}

\section{Introdução}

A N, N-dimetiltriptamina (DMT), figura 1, é um alcaloide indólico com potente ação alucinógena que pode ser obtido de forma exógena através de cogumelos, raízes, caules e folhas de diversas plantas, podendo ser encontrada também em tecidos de mamíferos, animais marinhos e anfíbios. Além disso, nos humanos, apresenta síntese endógena, sendo identificada no sangue, urina e no fluido cérebro-espinhal $[1,2]$.

No geral, dentre as plantas consideradas alucinógenas ou expansoras da mente, destaca-se, na produção da DMT, as folhas da espécie Psychotria viridis, comumente utilizada nos chás de rituais religiosos por tribos indígenas. Entretanto, devido à metabolização da DMT pelas isoenzimas monoamino oxidase (MAO) hepáticas e gastrointestinais, as folhas do arbusto são utilizadas juntamente do cipó da espécie Banisteriopsis caapi, que possui substâncias com potente capacidade de inibição temporária da MAO, aumentando o efeito da DMT [3].

A DMT é estruturalmente semelhante ao neurotransmissor serotonina (5-HT), visto que, ambos são sintetizados a partir do aminoácido essencial trip- tofano. Durante o processo de síntese da substância ocorre a reação de descarboxilação do aminoácido através da enzima aminoácido aromático descarboxilase (AADC), formando então a triptamina. A partir disso, a triptamina sofre ação da enzima indoletilamina-N-metiltransferase (INMT), responsável por introduzir um grupamento metil na molécula de triptamina. Ademais, outro grupamento metil é introduzido à $\mathrm{N}$-metiltriptamina, gerando então a N, N-dimetiltriptamina (DMT) [4].

Devido à similaridade com a serotonina, a DMT age como agonista parcial nos receptores serotoninérgicos (5-HT) pós-sinápticos [2]. Ela atua principalmente nos subtipos 5-HT1A, 5-HT2A e 5-HT2C, mas também podem ligar-se a receptores de glutamato, dopamina, acetilcolina, TAAR e sigma-1 [5]. Essas interações resultam no efeito alucinógeno, além de causar outros sintomas como diarreia, náuseas, vômitos, hipertensão, taquicardia e tremores, variando de acordo com a dosagem de DMT [2].

O presente trabalho tem como objetivo reunir dados e informações relacionadas aos efeitos terapêuticos e toxicológicos da DMT através de um levantamento bibliográfico de estudos realizados em 
humanos e animais que foram publicados no período de 2000 a 2019. Além disso, consideraram-se os efeitos causados pela Ayahuasca, uma vez que a mesma corresponde a principal forma de consumo de DMT.

\section{Material e Método}

Este estudo constitui-se de uma revisão bibliográfica realizada nas bases de dados Pubmed, SciELO e Google Acadêmico utilizando as palavras-chaves "dimetiltriptamina", "efeitos terapêuticos", "efeitos toxicológicos" e "Ayahuasca". A seleção dos artigos e periódicos foi feita de acordo com o seu ano de publicação, sendo inclusas somente as pesquisas realizadas a partir do ano 2000.

\section{Resultados}

\section{Chá de Ayahuasca}

A partir dos achados na literatura, identificamos que o chá de Ayahuasca é uma rica fonte de DMT, a bebida é conhecida pelo seu efeito alucinógeno e é utilizada, geralmente, por indígenas no noroeste da Amazônia para fins religiosos. Além da DMT, há também a presença de beta-carbolinas monoaminas oxidases, sendo elas harmina, tetrahidroharmina (THH) e harmalina, potentes inibidores que permitem a atividade oral da DMT, visto que, as mesmas são capazes de inibirem a enzima monoaminoxidase (MAO), permitindo assim, uma maior disponibilidade da molécula ao Sistema Nervoso Central (SNC) [6].

Figura 1: Estrutura química da N, N-dimetiltriptamina (DMT)

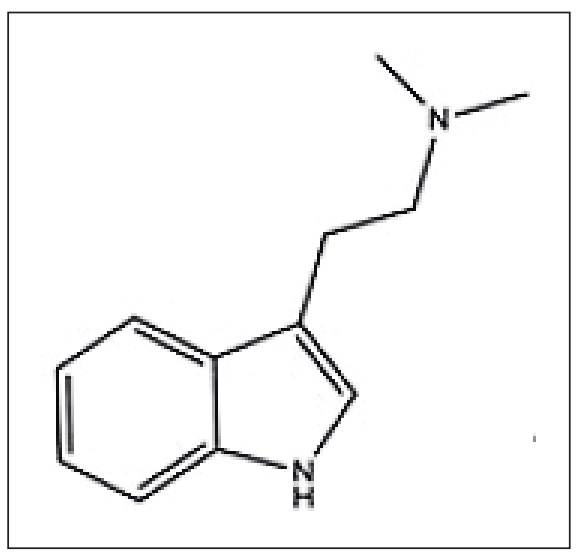

Figura 1. Fonte: Adaptado de Riba et al. [10].

\section{Farmacocinética e marcadores toxicológicos}

Em relação à farmacocinética da DMT, estudos observaram que os seus efeitos alucinógenos e o pico de concentração no sangue apresentam o tempo médio de 1,5 horas e os valores de base são atingidos após 6 horas de ingestão do chá [7]. Além disso, identificou-se que a inibição da MAO pelas $\beta$-carbolinas é de curta duração e principalmente periférica, porém, ainda que a inibição fosse parcial, já seria suficiente para causar efeitos psicoativos [8].

A partir de um método de espectrometria de massas com armadilha de íons de HPLC usando ionização por eletropulverização a quente desenvolvido em humanos para compreensão dos parâmetros bioquímicos, foi possível identificar os compostos ácido indolacético (IAA), DMT-N-óxido (DMT-NO), 5-hidroxi (OHDMT), N-metiltriptamina (NMT), 2 metil-tetrahidro-beta-carbolina (2-MTHBC) e o O-desmetilmetabolito de THH e 7-hidroxi-THH (THHOH), como os principais metabólitos encontrados no sangue e urina, através do consumo de DMT [9].

As análises mostraram que a DMT-NO foi o principal metabólito urinário, e também pode ser encontrada no sangue, atingindo concentrações maiores que a própria DMT. Além disso, observou-se aumentos significativos nos níveis plasmáticos de IAA, o qual foi explicado como uma possível inibição incompleta da MAO-A pelas $\beta$-carbolinas (harmalina, harmina e outras) [9].

Apesar dos inúmeros trabalhos citarem a desaminação oxidativa feita pela MAO como principal via de metabolização da DMT, segundo Riba et al. [10], esta não é a sua única via de metabolização, há também rotas alternativas como a N-oxidação, $\mathrm{N}$-desmetilação e ciclização, conforme observa-se na Figura 2.

\section{Farmacodinâmica}

A DMT é um composto que age principalmente nos receptores 5HT2A, 5HT2C e 5HT1A, sendo considerado um psicoativo quando injetado ou fumado, porém, quando ingerido, é metabolizado rapidamente pela atividade da monoamina oxidase (MAO-A) encontrada no trato gastrointestinal, por esse motivo, os alcalóides b-carbolina harmina, tetrahidroharmina (THH) e harmalina encontradas nas bebidas ritualísticas de Ayahuasca, agem como inibidores da MAO, tornando a DMT também um psicoativo por via oral [11]. 
Figura 2: Vias metabólicas da N, N-dimetiltriptamina. $\mathrm{MAO}=$ monoamina oxidase; ALDH = aldeído-desidrogenase.

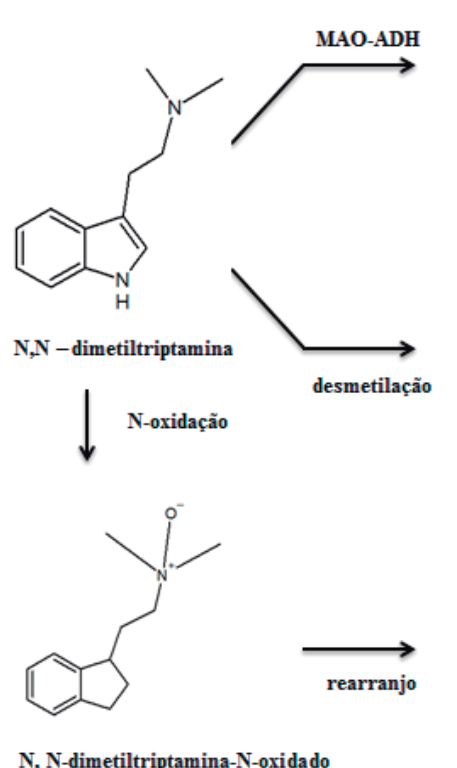

N, N-dimetiltriptamina-N-oxidado

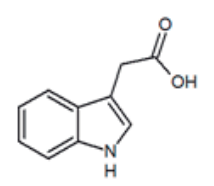

Ácido indolacético (AIA)
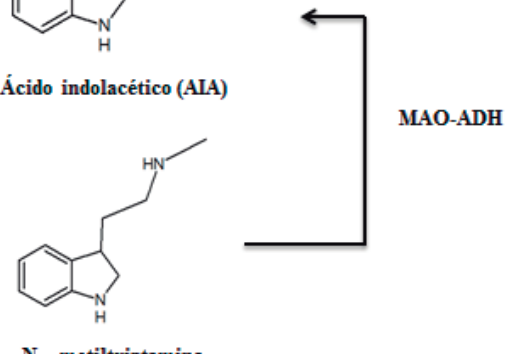

N-metiltriptamina

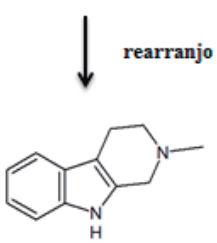

2-metil-tetrahidro-beta-carbolina

Figura 2. Fonte: Adaptado de Riba et al. [10].

O receptor 5-HT1A atua na diminuição do AMP cíclico (adenosina 3', 5'- monofosfato cíclico) e eleva a hiperpolarização da membrana, devido ao aumento da condução de K+. Entretanto, uma vez que os principais efeitos do chá de Ayahuasca são delírios, hipertensão, palpitação, taquicardia, tremores, midríase, euforia e excitação agressiva, além de náuseas, vômitos e diarreia, sugere-se que a maior ligação da DMT seja com os receptores 5-HT2, já que estes receptores estão distribuídos pelas plaquetas, músculo liso, córtex cerebral e estômago, e são responsáveis pelo aumento do $\mathrm{IP}_{3}$ (inositol trifosfato). $\mathrm{O}$ aumento desta substância está diretamente ligado ao aumento da secreção e da motilidade dos órgãos e tecidos [12].

\section{Efeitos terapêuticos}

Nos últimos anos, a quantidade de estudos e revisões sistemáticas sobre o potencial efeito terapêutico oferecido pelos componentes do chá de Ayahuasca vem aumentando, considerando que os resultados obtidos têm demonstrado a eficácia dessas substâncias no tratamento contra a dependência de álcool e tabaco, além de apresentar efeitos antidepressivo e ansiolítico [13].

Através de um questionário realizado na Austrá- lia com usuários do chá de Ayahuasca entre julho e agosto de 2009 , cerca de $75 \%$ dos entrevistados consideraram a experiência com o chá significativa e 55\% consideraram o uso do chá como uma boa experiência espiritual. Em outra pesquisa feita também na Austrália com participantes que relataram o uso de DMT pelo menos uma vez na vida, obteve-se a informação de que em $31,1 \%$ dos casos foi citado que a DMT possuía benefícios psicoterapêuticos. Foi notório um aumento significativo no uso psicoespiritual da substância, sendo informado em $75,5 \%$ dos casos como um efeito positivo da DMT fumada, e o uso da Ayahuasca, com 31,1\% dos casos [14].

Segundo dos Santos et al. [15], o agonismo nos receptores corticais 5-HT2A podem estimular a neurotransmissão de glutamato e pode aumentar a expressão de fatores neurotróficos, como o BDNF e o GDNF, que correspondem, respectivamente, ao fator neurotrófico derivado do cérebro e ao fator neurotrófico derivado da linha celular glial. Estes fatores favorecem a neuroplasticidade e a neurogênese, aumentando o tamanho de espinhos dendríticos em neurônios corticais.

Recentemente, em um estudo realizado com primatas $(n=15)$ para avaliar o efeito antidepressivo do chá de Ayahuasca, os animais foram separados de seus 
respectivos grupos, induzindo-os então a depressão, os mesmos não poderiam ter qualquer tipo de contato a não ser olfatório e auditivo. Durante o estudo, todos os animais foram tratados com uma única dose de Ayahuasca (1,67 mL/300 g de peso corporal via gavagem). Os efeitos comportamentais e fisiológicos foram avaliados 24 horas e 48 horas após a administração do chá e foram considerados rápidos e positivos, demonstrando redução da depressão e de coceira (efeito estereotipado) nos animais. Além disso, houve um aumento na taxa de alimentação e recuperação do peso corporal dos primatas, assim como os níveis de cortisol mantiveram-se conforme os valores de base [16].

Já em um estudo feito com ratos Wistars fêmeas, foi administrado Ayahuasca em doses de 30x e 50x sendo que a análise mostrou que a infusão de ayahuasca continha $0,141 \mathrm{mg} / \mathrm{mL}$ de DMT, $1,56 \mathrm{mg} /$ $\mathrm{mL}$ de harmina e $0,122 \mathrm{mg} / \mathrm{mL}$ de harmalina, onde uma dose da infusão $(150 \mathrm{~mL})$ corresponde a 0,302 $\mathrm{mg} / \mathrm{kg}$ de DMT, 3,34 mg/kg de harmina e $0,261 \mathrm{mg} /$ $\mathrm{kg}$ de harmalina. Os resultados demonstraram uma ativação neuronal nas regiões que apresentavam neurotransmissão serotoninérgica e efeitos antidepressivos. Em relação a esses resultados, observou-se que os compostos contidos na Ayahuasca, na qual possuem ação nas vias serotoninérgicas, participam desse processamento emocional em relação à depressão [17].

Santos et al. [18], avaliaram um grupo de pessoas que faziam parte do ritual Santo Daime e utilizavam o chá de Ayahuasca por pelo menos 10 anos. O teste controlado por placebo, tinha a finalidade de avaliar as condições emocionais, como pânico, desesperança e ansiedade, sendo que, após 1 hora da ingestão da Ayahuasca, através de um questionário os voluntários relataram redução desses sintomas.

Em outro estudo mais recente [19], foi avaliado a ingestão de uma dose de Ayahuasca em 17 pacientes de uma clínica psiquiátrica que apresentavam diferentes níveis de depressão. Após 8 horas, foi realizada uma tomografia computadorizada por emissão de fóton único que identificou o aumento da perfusão sanguínea no núcleo esquerdo accumbens, ínsula direita e área subgenual esquerda, que são regiões do cérebro envolvidas na regulação do humor e das emoções e que são relacionadas aos efeitos terapêuticos dos antidepressivos tradicionais. Assim, como resultado houve diminuição da depressão e aumento da psicoatividade.
Cameron et al. [20] conduziram um estudo com ratos machos adultos, nos quais foram aplicados dimetiltriptamina para avaliar o comportamento de ansiedade e depressão dos mesmos, concluindo que os efeitos duradouros da DMT têm a capacidade de reduzir a ansiedade e facilitar a extinção da memória de medo.

Um estudo realizado in vitro, proporcionou a descoberta de que a molécula dimetiltriptamina tem atuação sob a enzima indoleamina-2,3 dioxigenase (IDO), essa enzima faz parte do processo imunológico do tumor. Assim, foi possível identificar uma atividade antitumoral da DMT, que demonstrou atuar como inibidora não competitiva da enzima indoleamina-2,3 dioxigenase (IDO) e também apresentou uma atividade citotóxica nas células mononucleares no sangue periférico e atividade inibitória na linha celular de glioma [21].

Em outro teste realizado in vitro, foi possível identificar que a dimetiltriptamina possui relação com os receptores sigma-1, a partir disso, percebeu-se uma atividade anti-inflamatória devido a DMT modular esse receptor e gerar efeitos nos canais de íons [22]. Essa ação no receptor sigma-1, interfere nos canais de íons provocando um influxo de cálcio para as mitocôndrias, gerando despolarização da membrana mitocondrial e, consequentemente, um desequilíbrio energético que resulta na indução das células a sofrerem apoptose [23,24].

Em um estudo feito com o intuito de analisar os efeitos da Ayahuasca sobre o sistema imunológico, 10 voluntários foram submetidos à ingestão do chá. Como resultado, houveram aumentos significativos nos níveis de cortisol e de células natural killer (NK), além de reduções significativas nos níveis de linfócitos CD3 e CD4 [25]. Segundo dos Santos [25], isso pode ser causado pela ação agonista da DMT sobre os receptores 5-HT2A centrais e periféricos em leucócitos e outras células ou tecidos imunológicos, prejudicando sua diferenciação e funcionalidades. Ainda assim, as alterações dos níveis de linfócitos não representam riscos patológicos e o aumento das células NK pode ser favorável no combate a células cancerígenas ou infectadas por vírus [26].

Recentemente, um estudo relatou que a DMT causa aumento expressivo dos níveis de interferon- $\gamma$ e interferon- $\beta$ em culturas de células NK humanas e células dendrítricas em seguida a administração in vitro, indicando que esse efeito pudesse ter intervin- 
do pelo receptor sigma-1, revelando um aumento nas expressões dos genes do interferon tipo I e II nessas células, mas não sendo relacionado a mutações no mRNA, nem nos níveis de proteína das citocinas inflamatórias [27].

No entanto, em um estudo mais recente, foram investigados os efeitos do DMT e da 5-metoxi-N, $\mathrm{N}$-dimetiltriptamina (5-MeO-DMT) nos receptores sigma-1 em células imunes mielóides humanas sob condições inflamatórias e foi constatado que ambos reduziram o mRNA e os níveis secretados das citocinas pró-inflamatórias IL- $1 \beta$, IL-6, TNFa e quimiocina IL-8, enquanto elevaram a secreção da citocina anti-inflamatória IL-10. Assim, cessou-se a possibilidade de as células mieloides humanas desencadearem respostas imunes adaptativas mediadas pelas células inflamatórias T auxiliar 1 (Th1) e T auxiliar 17 (Th17) [28].

Um estudo in vitro referiu que a DMT foi constatada no sobrenadante de uma linha celular de melanoma, onde a oxidação da DMT foi catalizada por peroxidases e, sugerindo então pelos autores que, como a atividade da peroxidase é largamente identificada em condições inflamatórias, a metabolização da DMT pode ser pertinente em patologias onde há inflamação [29].

A Ayahuasca pode auxiliar no tratamento de alguns tipos de distúrbios como uso abusivo de substâncias químicas e alcoolismo. Em uma notícia anunciada em uma rádio $(\mathrm{BBC})$ foi relatado o uso bem-sucedido da Ayahuasca no tratamento de dependentes de cocaína em uma clínica de reabilitação localizada no Peru. Isso indicou que o tratamento com a Ayahuasca, em um contexto psicoterapêutico pode ser realmente eficaz. Um estudo teve como objetivo confirmar o uso da Ayahuasca no tratamento de alcoolismo. Nele, os candidatos selecionados para participar do estudo deveriam passar por tecnologias de neuroimagem com o intuito de rastreá-las inicialmente quanto à existência de déficits de transportadores de serotonina central A interrupção da ingestão do álcool esteve interligada com o uso da Ayahuasca, causando elevação de longo prazo na densidade dos transportadores de $5-\mathrm{HT}$ em plaquetas [6].

\section{Efeitos toxicológicos}

Existem poucos relatos sobre reações graves com risco de vida envolvendo a DMT no uso da Ayahuas- ca. Alguns relatos televisivos e revistas descreveram casos fatais isolados, e outros sobre reações adversas, entretanto, os achados não forneceram evidências forenses, como, por exemplo, autopsia de composições químicas do composto ingerido, análise de sangue para alcaloides beta-carbolina, composição da bebida e quantidade ingerida [30].

Segundo Bilhimer et al. [30], há preocupações sobre interações da Ayahuasca e substâncias inibidoras da MAO, assim como, medicações serotoninérgicas, considerando a rota de metabolização da DMT pela MAO e o mecanismo de ação nos receptores de serotonina, respectivamente, que podem resultar na síndrome de serotonina. Este fenômeno não foi observado comumente em pessoas que utilizam antidepressivos concomitantemente com Ayahuasca, entretanto, os casos existem.

A síndrome de serotonina é um evento que pode ser potencialmente fatal e que envolve o excesso de estimulação dos receptores de serotonina (principalmente os receptores 5-HT1A e 5-HT2A) no sistema nervoso periférico e central. Este incidente pode ocorrer com o excesso de exposição a drogas serotoninérgicas, como Inibidores Seletivos da receptação de serotonina (ISRS) e/ou inibidores da MAO [31,32].

Referente ao uso da Ayahuasca em mulheres grávidas e adolescentes, os únicos estudos que avaliaram alguns destes aspectos, concluíram que adolescentes expostos ao chá de Ayahuasca em vários estágios de seu desenvolvimento, desde o útero, incluindo infância e adolescência, foram considerados normais do ponto de vista psiquiátrico, psicológico e neuropsicológico. Entretanto, vale ressaltar que não há publicações científicas sobre efeitos tóxicos da Ayahuasca em mulheres grávidas ou até mesmo no feto, apesar do consumo de Ayahuasca por anos em rituais [32].

Em um estudo realizado com ratas prenhas, os animais foram tratados com Ayahuasca por via oral $(1 \mathrm{x}, 2 \mathrm{x}, 4 \mathrm{x}$ e $8 \mathrm{x}$ a dose ingerida por um adulto saudável durante um ritual religioso), sendo que a dose humana equivalente (1X) desta infusão corresponde a $0,30 \mathrm{mg} / \mathrm{kg} \mathrm{pc} / \mathrm{dia} \mathrm{DMT}$, do sexto ao vigésimo dia de gestação e no vigésimo primeiro dia foram avaliadas as informações coletadas do estudo. Cerca de $44 \%$ dos animais tratados com $4 \mathrm{x}$ a dose normal ingerida por um humano morreram durante o estudo, enquanto que, $52 \%$ dos animais tratados com $8 x$ a dose normal, também morreram, a parte sobrevivente apresentou efeitos tóxicos como, por exemplo, perdas neuronais, 
atraso no crescimento intrauterino, óbitos induzidos por embriões e aumento da ocorrência de anomalias fetais, além de degenerações hidrópicas nas células renais dos animais [33].

A hipótese mais plausível para a morte dos animais envolvidas no estudo anterior descrito é de que a Ayahuasca apresentou efeitos neurotóxicos, visto que, antes das mortes registradas as amostras apresentaram tremores, rigidez, hiperextensão dos membros posteriores e convulsões, sintomas típicos de uma síndrome de serotonina [33].

Em outro estudo, sintomas como diarreia, náusea e vômito, assim como elevação de frequência cardíaca e pressão arterial foram observados após o consumo da DMT [20,34]. Também foi verificado que uma dose oral de $1 \mathrm{mg} / \mathrm{kg}$ de DMT é suficiente para o aparecimento desses efeitos. Quando administrado por via intravenosa, pequenas doses entre 0,1 e $0,2 \mathrm{mg} /$ $\mathrm{kg}$ já são suficientes para ocasionar os efeitos supracitados [35].

A dose oral letal média para $50 \%$ da população (DL50) de DMT é de $8 \mathrm{mg} / \mathrm{kg}$. Esse dado foi obtido através de experimentos com animais de laboratório, estimando que uma dose total letal para um adulto de $70 \mathrm{~kg}$ é de $560 \mathrm{mg}$. Em cerimônias, é consumido em média uma dose de cerca de $27 \mathrm{mg}$. Levando em consideração a DL50, podemos supor que a margem de segurança para o uso de Ayahuasca é de aproximadamente $0,385 \mathrm{mg} / \mathrm{kg}$ para um indivíduo adulto e saudável de $70 \mathrm{~kg}$ [34].

\section{Conclusão}

Baseando-se nos resultados apresentados durante esta revisão de literatura, pode-se concluir que o chá de Ayahuasca e o seu componente alucinógeno DMT apresentam grande potencial terapêutico, com efeitos que incluem benefícios psicoterapêuticos, ação antidepressiva e antitumoral, despertando cada vez mais o interesse da comunidade científica.

Apesar dos seus importantes aspectos farmacológicos, a DMT também pode causar efeitos adversos consideráveis, incluindo toxicidade, o que corrobora com a necessidade da realização de mais testes agudos e crônicos, além de pesquisas epidemiológicas focadas na sua ação nas populações que a utilizam, considerando a limitação de estudos e dados sobre esse assunto.

\section{Referências}

1. Strassman R. DMT: The spirit molecule, a doctor's revolutionary research into the biology of neardeath and mystical experiences. South Paris, ME: Park Street Press, 2001.

2. Almeida DF, Silva ALP, Assis TJCF. Dimethyltryptamine: hallucinogenic alkaloid on the Central Nervous System. Acta Brasiliensis. 2018; 2(1); 28-33. http://www.revistas.ufcg.edu.br/ActaBra/index.php/ actabra/article/view/43.

3. De Souza PA. Alcaloides e o chá de ayahuasca: uma correlação dos "estados alterados da consciência" induzido por alucinógenos. Rev. bras. plantas med. 2011; 13 (3): 349-358. http://www.scielo.br/ scielo.php?pid $=S 1516=05722011000300015-\&$ scriptsci arttext\&tlng=pt.

4. Gomes MM. Dietilamida do ácido lisérgico (LSD) e N,N-dimetiltriptamina (DMT) como substratos de peroxidases: uma possível rota de metabolização [dissertação]. São Paulo: Universidade de São Paulo, Faculdade de Ciências Farmacêuticas; 2008.

5. Carbonaro TM, Gatch MB. Neuropharmacology of N, N-dimethyltryptamine. Brain research bulletin. 2016; 126: 74-88. https://www.sciencedirect.com/ science/article/abs/pii/S0361923016300909.

6. McKenna, DJ. Clinical investigations of the therapeutic potential of ayahuasca: rationale and regulatory challenges. Pharmacology \& therapeutics. 2004; 102(2), 111-129. https://www.sciencedirect.com/science/article/abs/pii/S0163725804000464.

7. Riba J, Valle M, Urbano G, Yritia M, Morte A, Barbanoj MJ. Human pharmacology of ayahuasca: subjective and cardiovascular effects, monoamine metabolite excretion, and pharmacokinetics. Journal of Pharmacology and Experimental Therapeutics. 2003; 306(1): 73-83. http://jpet.aspetjournals.org/ content/306/1/73.short.

8. Domínguez-Clavé E, Soler J, Elices M, Pascual JC, Álvarez E, de la Fuente Revenga M et al. Ayahuasca: pharmacology, neuroscience and therapeutic potential. Brain research bulletin. 2016; 126: 89-101. https://www.sciencedirect.com/science/article/abs/ pii/S0361923016300454.

9. McIlhenny EH, Riba J, Barbanoj MJ, Strassman R, Barker, S. A. Methodology for determining major constituents of ayahuasca and their metabolites in blood. Biomedical Chromatography. 2012; 26(3): 301313. https://onlinelibrary.wiley.com/doi/abs/10.1002/ 


\section{bmc. 1657.}

10. Riba J, McIlhenny EH, Valle M, Bouso JC, Barker SA. Metabolism and disposition of N, N-dimethyltryptamine and harmala alkaloids after oral administration of ayahuasca. Drug testing and analysis. 2012; 4(7-8): 610-616. https://onlinelibrary.wiley. com/doi/abs/10.1002/dta.1344.

11. Barbosa PCR, Mizumoto S, Bogenschutz MP, Strassman RJ. Health status of ayahuasca users. Drug testing and analysis. 2012; 4(7-8): 601-609. https://onlinelibrary.wiley.com/doi/abs/10.1002/dta.1383.

12. Costa MCM, Figueiredo MC, Cazenave SDOS. Ayahuasca: uma abordagem toxicológica do uso ritualístico. Rev. psiquiatr. Clín.. 2005; 32(6), 310-318. http://www.scielo.br/scielo.php?script=sci_arttext\&pid $=$ S0101-60832005000600001\&lng $=$ pt\&nrm $=\mathrm{i}-$ so.

13. Souza RC, Zandonadi FS, Freitas DP, Tófoli LF, Sussulini A. Validation of an analytical method for the determination of the main ayahuasca active compounds and application to real ayahuasca samples from Brazil. Journal of Chromatography B. 2019; 1124: 197-203. https://www.sciencedirect.com/science/article/abs/pii/S1570023219301825.

14. Cakic V, Potkonyak J, Marshall A. Dimethyltryptamine (DMT): Subjective effects and patterns of use among Australian recreational users. Drug and alcohol dependence. 2010; 111(1-2): 30-37. https:// www.sciencedirect.com/science/article/abs/pii/ $\underline{\text { S0376871610001341. }}$.

15. Dos Santos RG, Osorio FL, Crippa JAS, Hallak JE. Classical hallucinogens and neuroimaging: A systematic review of human studies: Hallucinogens and neuroimaging. Neuroscience \& Biobehavioral Reviews. 2016; 71: 715-728. https://www.sciencedirect. com/science/article/abs/pii/S0149763416302354.

16. Da Silva FS, Silva EA, Sousa Jr GMD, Maia-de-Oliveira JP, Soares-Rachetti VDP, de Araujo DB et al. Acute effects of ayahuasca in a juvenile non-human primate model of depression. Brazilian Journal of Psychiatry. 2019; 41(4), 280-288. http://www.scielo. br/scielo.php?pid=S1516-44462018005009104\&scri $\mathrm{pt}=\mathrm{sci}$ arttext.

17. Pic-Taylor A, da Motta LG, de Morais JA, Junior WM, Santos ADFA, Campos LA et al. Behavioural and neurotoxic effects of ayahuasca infusion (Banisteriopsis caapi and Psychotria viridis) in female Wistar rat. Behavioural processes. 2015; 118: 102-110. https://www.sciencedirect.com/science/arti-
cle/abs/pii/S0376635715001278.

18. Santos RD, Landeira-Fernandez J, Strassman RJ, Motta V, Cruz APM. Effects of ayahuasca on psychometric measures of anxiety, panic-like and hopelessness in Santo Daime members. Journal of ethnopharmacology. 2007; 112(3): 507-513. https:// www.sciencedirect.com/science/article/abs/pii/ $\underline{\text { S0378874107002139. }}$.

19. Osório FDL, Sanches RF, Macedo LR, Dos Santos RG, Maia-de-Oliveira JP, Wichert-Ana L et al. Antidepressant effects of a single dose of ayahuasca in patients with recurrent depression: a preliminary report. Brazilian Journal of Psychiatry. 2015; 37(1): 13-20. http://www.scielo.br/scielo.php?pid=S1516-44 $\underline{462015000100013 \& \text { script }=\text { sci } \_ \text {arttext\&tlng }=\text { pt. }}$.

20. Cameron LP, Benson CJ, Dunlap LE, Olson DE. Effects of N, N-dimethyltryptamine on rat behaviors relevant to anxiety and depression. ACS chemical neuroscience. 2018; 9(7): 1582-1590. https://pubs.acs. org/doi/abs/10.1021/acschemneuro.8b00134.

21. Tourino MC, de Oliveira EM, Bellé LP, Knebel FH, Albuquerque RC, Dörr FA et al. Tryptamine and dimethyltryptamine inhibit indoleamine 2, 3 dioxygenase and increase the tumor-reactive effect of peripheral blood mononuclear cells. Cell biochemistry and Function. 2013; 31(5): 361-364. https://onlinelibrary.wiley.com/doi/abs/10.1002/cbf.2980.

22. Cozzi NV, Gopalakrishnan A, Anderson LL, Feih JT, Shulgin AT, Daley PF et al. Dimethyltryptamine and other hallucinogenic tryptamines exhibit substrate behavior at the serotonin uptake transporter and the vesicle monoamine transporter. Journal of neural transmission. 2009; 116(12): 1591. https://link. springer.com/article/10.1007/s00702-009-0308-8.

23. Walter L, Hajnóczky G. Mitochondria and endoplasmic reticulum: the lethal interorganelle crosstalk. Journal of bioenergetics and biomembranes. 2005; 37(3): 191-206. https://link.springer.com/article/10.1007/s10863-005-6600-x.

24. Jose C, Bellance N, Rossignol R. Choosing between glycolysis and oxidative phosphorylation: a tumor's dilemma? Biochimica et Biophysica Acta (BBA)-Bioenergetics. 2011; 1807(6): 552-561. https://www.sciencedirect.com/science/article/pii/ $\underline{\text { S0005272810007206. }}$.

25. Dos Santos RG. Ayahuasca physiological and subjective effects, comparison with d-amphetamine, and repeated dose assessment. Barcelona: Universitat Autònoma de Barcelona, Departament de Farmacolo- 
gia, Terapèutica i de Toxicologia: 2012.

26. Dos Santos RG. Immunological effects of ayahuasca in humans. Journal of psychoactive drugs. 2014; 46(5): 383-388. https://www.tandfonline.com/ doi/abs/10.1080/02791072.2014.960113.

27. Frecska E, Szabo A, Winkelman MJ, Luna LE, Mckenna DJ. A possibly sigma-1 receptor mediated role of dimethyl- tryptamine in tissue protection, regeneration, and immunity. Journal of Neural Transmission. 2013; 120(9): 1295-303. https://link.springer.com/article/10.1007/s00702-013-1024-y.

28. Szabo A, Kovacs A, Frecska E, Rajnavolgyi E. Psychedelic N, N-dimethyltryptamine and 5-methoxy-N, N-dimethyltryptamine modulate innate and adaptive inflammatory responses through the sigma-1 receptor of human monocyte-derived dendritic cells. PloS one. 2014; 9(8): e106533. https:// journals.plos.org/plosone/article? id=10.1371/journal.pone. 0106533 .

29. Gomes MM, Coimbra JB, Clara RO, Dörr FA, Moreno ACR, Chagas JR et al. Biosynthesis of N, N-dimethyltryptamine (DMT) in a melanoma cell line and its metabolization by peroxidases. Biochemical pharmacology. 2014; 88(3): 393-401. https://www.sciencedirect.com/science/article/pii/S0006295214000744.

30. Bilhimer MH, Schult RF, Higgs KV, Wiegand TJ, Gorodetsky RM, Acquisto NM. Acute Intoxication following dimethyltryptamine ingestion. Case reports in emergency medicine. 2018; 2018: 1-3. https://www. hindawi.com/journals/criem/2018/3452691/.

31. Volpi-Abadie J, Kaye AM, Kaye AD. Serotonin syndrome. The Ochsner Journal. 2013; 13(4): 533-540. https://www.ncbi.nlm.nih.gov/pmc/articles/ PMC3865832/.

32. Dos Santos, RG. Safety and side effects of ayahuasca in humans - an overview focusing on developmental toxicology. Journal of psychoactive drugs. 2013; 45(1): 68-78. https://www.tandfonline.com/doi/ abs/10.1080/02791072.2013.763564.

33. Da Motta LG, de Morais JA, Tavares ACA, Vianna LMS, Mortari MR, Amorim RFB et al. Maternal and developmental toxicity of the hallucinogenic plant-based beverage ayahuasca in rats. Reproductive Toxicology. 2018; 77: 143-153. https://www.sciencedirect.com/science/article/pii/S0890623817307037.

34. Gable RS. Risk assessment of ritual use of oral dimethyltryptamine (DMT) and harmala alkaloids. Addiction. 2007; 102(1): 24-34. https:// onlinelibrary.wiley.com/doi/abs/10.1111/j.1360-

\subsubsection{2.x.}

35. Riba J, Rodríguez-Fornells A, Urbano G, Morte A, Antonijoan R, Montero M. Subjective effects and tolerability of the South American psychoactive beverage Ayahuasca in healthy volunteers. Psychopharmacology. 2001; 154(1): 85-95. https://link.springer. com/article/10.1007/s002130000606. 